\title{
SHM by DOFS in civil engineering: a review
}

\author{
Gerardo Rodríguez ${ }^{a}$, Joan R. Casas ${ }^{*}$ and Sergi Villalba ${ }^{b}$ \\ UPC, Department of Construction Engineering, Technical University of Catalonia- BARCELONATECH, \\ Jordi Girona 1-3, 08034 Barcelona, Spain
}

(Received April 14, 2015, Revised July 28, 2015, Accepted July 30, 2015)

\begin{abstract}
This paper provides an overview of the use of different Distributed Optical Fiber Sensor systems (DOFSs) to perform Structural Health Monitoring (SHM) in the specific case of civil engineering structures. Nowadays, there are several methods available for extracting distributed measurements from optical fiber, and their use have to be according with the aims of the SHM performance. The continuous-in-space data is the common advantage of the different DOFSs over other conventional health monitoring systems and, depending on the particular characteristics of each DOFS, a global and/or local health structural evaluation is possible with different accuracy. Firstly, the fundamentals of different DOFSs and their principal advantages and disadvantages are presented. Then, laboratory and field tests using different DOFSs systems to measure strain in structural elements and civil structures are presented and discussed. Finally, based on the current applications, conclusions and future trends of DOFSs in SHM in civil structures are proposed.
\end{abstract}

Keywords: structural health monitoring; distributed optical fiber; Brillouin and Rayleigh backscattering

\section{Introduction}

The aging infrastructure constitutes an unavoidable issue around the world. Buildings, bridges, dams and power plants are examples of this decay process. Their durability is an important issue with economic, social and environmental impacts. Therefore, civil structures maintenance is a high challenge in structural engineering. Nowadays and thanks to several SHM technical developments, an important number of civil structures are monitored as part of its maintenance. In this context, SHM can be seen as the continuous or regular measurement and analysis of key structural and environmental parameters in operation conditions, for the purpose of warning of abnormal states or accidents at an early stage (Housner et al. 1997). Within the variety of monitoring systems, SHM systems based on the use of fiber optic sensors have gained an important place and their use is increasingly being accepted. Their small dimensions, rapid data transmission and immunity from electromagnetic influences are some of the adventages of the optical sensors over electrical traditional instruments (Casas and Cruz 2003, Culshaw 2011, Glisic and Inaudi 2007, Ye et al. 2014). Most optical fiber sensors as Fiber Bragg Grating (FBG) (Todd et al. 2001) and Fabry-Perot (Ye et al. 2014) are discrete and only local measurements are obtained with their use. However,

*Corresponding author, Professor, E-mail: joan.ramon.casas@upc.edu

${ }^{a}$ Ph.D. Student, E-mail: gerardo.rodriguez@estudiant.upc.edu

${ }^{\mathrm{b}}$ Ph.D., E-mail: sergio.villalba@upc.edu

Copyright $\odot 2015$ Techno-Press, Ltd. 
several FBG can be centered at different wavelengths and conform a FBG group at the same optical fiber. Then, this FBG group can be interrogated at the same time and multiplexed to conform a quasi-distributed sensing system (Majumder et al. 2008). A major application of FBG sensors in the field of SHM, is the use of these quasi-distributed measurement techniques in the active control of long-span bridges (Tennyson et al. 2001, Lin et al. 2005, Gómez et al. 2009), especially concrete bridges, are the most monitored civil engineering structures by optical fiber sensors (Tennyson et al. 2001). In these cases, to understand the structural behavior a high number of sensors is required, and for this reason, SHM system could be very expensive. Even so, FBG sensors can only provide discrete measurements, and important data away of the FBG sensors could be lost. To deal with the above limitation, optical fiber ability of monitoring physical fields (strains, temperatures, chemical concentrations) has been exploited to develop different Distributed Optical Fiber Sensor systems (DOFSs). DOFSs (Rogers 1999) offer the unique ability of monitoring strain and temperature variations with spatial continuity along the optical fiber. Also, DOFSs are most suitable for large structural applications (Li 2004), since all the segments of an optical fiber act as sensors, and therefore, the perturbations within various hundreds of meters, even kilometers of the structure can be measured. In general, DOFSs techniques consist of injecting a laser pulse within an optical fiber and then measuring the backscattered intensity variations over the length fiber deployed in a civil engineering structure (Delepine-Losoille et al. 2008). Through these intensity variations, strain and temperatures along the structure have been obtained. As a continuous distributed sensing method, spatial resolution and strain measurement accuracy are the main concern of a DOFSs (Zhang and Wu 2008). In the first practical applications of DOFSs, $1 \mathrm{~m}$ spatial resolution was used, because it was the maximum spatial resolution that could be obtained with DOFS at that time. Applying different DOFSs, the evaluation of concrete and steel bridges, and others structures had performed successfully (Enckell et al. 2011, Minardo et al. 2012, Bastiniani et al. 2005a, Bastiniani et al. 2005b). However, if one of the principal aims of a SHM process is the implementation of a damage identification strategy (Liu and Nayak 2012), and the SHM system is based on DOFSs with $1 \mathrm{~m}$ spatial resolution, valuable data about structural damage could be lost. For example, opening cracks of the order of millimeters as sign of severe structural damage is shorter than the DOFSs $1 \mathrm{~m}$ spatial resolution. When sensing length of the distributed optical sensor, in this case in order of millimeters, is shorther than the spatial resolution, the measured strain is supposed to be the average strain within the spatial resolution, which results in measurement errors (Zhang and Wu 2008). It is critical in the applications of DOFSs with $1 \mathrm{~m}$ spatial resolution for crack width or localized damage monitoring and measurement in civil structures. However, recent developments with different DOFS have greatly increased the spatial resolution and strain and temperature measurement accuracy, enabling the use of sensing length similar to conventional strain gauges with microstrain accuracy and submillimetrical spatial resolution (Villalba et al. 2012, Regier and Hoult 2014). This paper presents a rewiew of DOFSs in the field of the SHM, in the specific case of civil engineering structures. A background of the physical fundamentals of DOFSs thechniques are provided. Then, different applications of DOFSs in civil structures are presented. Finally, conclusions and future aims of DOFSs in SHM in concrete structures are proposed.

\section{Fundamentals of Distributed Optical Fiber Sensor systems (DOFS)}

In every DOFSs the sensor is an optical fiber embedded into a cladding and sometimes into a 
specially designed cable. One of the principal characteristics of optical fibers is their diameter around $125 \mathrm{~m}$ as a human hair. Inside of this small diameter, the two key elements are the core and the cladding. The core is the inner part of the fiber, which guides the light and the cladding surrounds it completely. Light is guided in the core of an optical fiber by internal reflection, which is produced because the refractive index of the core is higher than that of the cladding, so light in the core that strikes the boundary at an acceptance angle is confined in the core by total internal reflection, as shown in Fig. 1 (Hetch 2006).

Light which travels into the optical fiber core is in general a monochromatic laser. In the process described above, attenuation is one of the most important properties of an optical fiber influencing the light transmission. Therefore, if an optical fiber is used as a communication channel, attenuation has to be minimized. But if the optical fiber is used as a sensor, the attenuation could be exploited. There are several sources of attenuation. Scattering is the most important light phenomenon to understand the DOFSs measurements techniques.

\subsection{Scattering}

In a general sense, scattering is the interaction of light with an optical medium. In an optical fiber, this medium is the fiber core, here a scattering occurs under conditions that the optical properties of the core are modified at the presence of the incident light wave (Boyd 1992). When a monochromatic source of light conformed by continuous waves is launched through at one of the ends of a fiber optic, a high percentage of light waves continues their path toward the other end of the fiber. However, other percentage of them hits with particles or dopants that conform the fiber optic and some light waves are scattered in different directions. These molecular perturbations between light waves and dopants are produced in the fiber core as shown in Fig. 2.

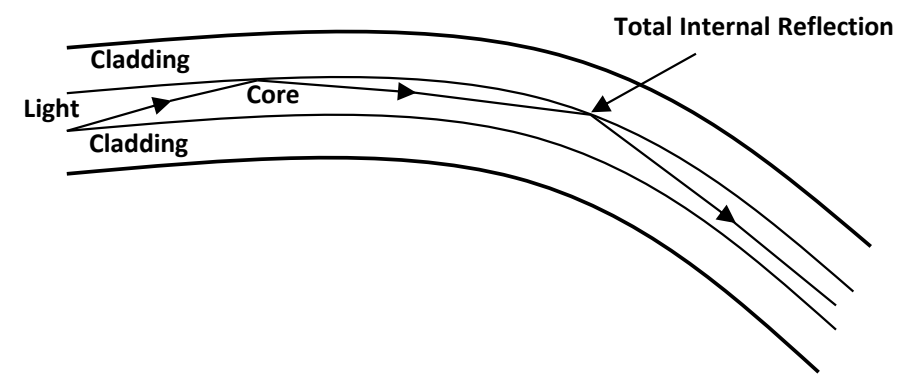

Fig. 1 Light guiding and total internal reflection in an optical fiber

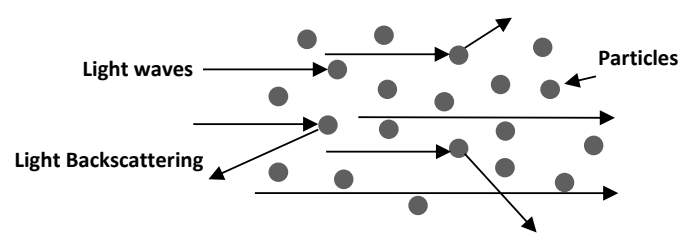

Fig. 2 Scattering and backscattering into the core of an optical fiber 


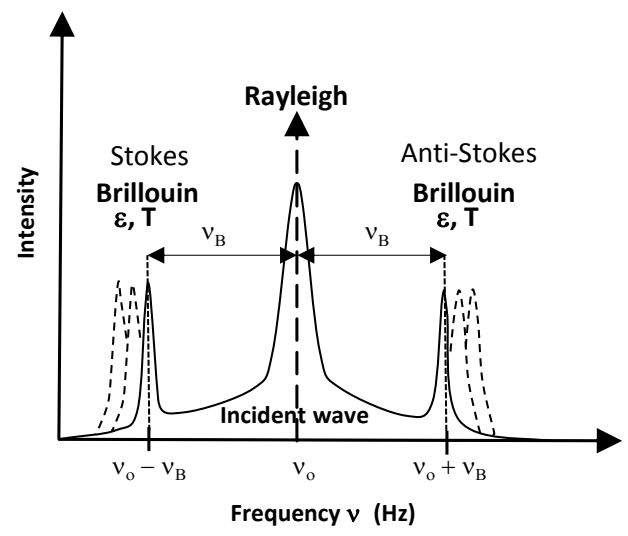

Fig. 3 Rayleigh and Brillouin spectral components in backscattered light

To analyze scattering into the optical fiber core, the wave-particle duality of light is used. Now, light is conformed by photons or light wave packets with a specific frequency. When scattering occurs, a number of photons return toward the source of light and backscattering is produced. In this internal process, an energy interchange occurs and photons maintain or change their frequencies. If frequency does not shift, an elastic scattering is produced, but when frequency shifts, an inelastic scattering is performed. In the scattering, three physical phenomena take place at every point in optical fiber: Rayleigh, as elastic scattering, and Raman and Brillouin as inelastic scattering. Being the two internal processes most commonly used in the DOFSs systems applied in SHM, only Rayleigh and Brillouin scattering will be described.

\subsection{Rayleigh scattering}

Rayleigh scattering occurs due to the random impact of the incident light with particles much smaller than the light wavelength, and only microscopic variations in refraction index of the fiber core are produced ( $\mathrm{Yu}$ and Yin 2002). For this reason, Rayleigh scattering is considered a quasi-elastic or linear phenomena (Boyd 1992), which presents the same frequency $\left(v_{o}\right)$ between incident light and backscattered photons as shown in Fig. 3. Also, predominant Rayleigh scattering is depicted in this figure. The backscattering Rayleigh intensity is approximately $20 \mathrm{~dB}$ greater than backscattered Brillouin (Horiguchi et al. 1995).

\subsection{Brillouin scattering}

Brillouin scattering is produced by the interaction between the light and sound (Boyd 1992). It occurs when the light intensity reaches a level sufficient to generate a termal effect into the fiber core. At this moment, the density of the material changes and very small acoustic waves in the optical fiber core are produced (Hetch 2006, Boyd 1992). The acoustic waves with a frequency $\left(v_{a}\right)$ travel along the fiber core at sound velocity and they interfere with light photons. Changes in these interacting waves are produced and one of this it is the periodic change in the light refractive 
index. Due to the fact that the periodic shift in the refractive index of the medium is moving at sound velocity with acoustic wave, the diffracted light undergoes a Doppler frequency shift. The interaction between light waves with a frequency $\left(v_{o}\right)$ and moving acoustic waves with a frequency $\left(v_{a}\right)$ can also be seen as a moving Bragg diffraction (Zeni 2009) as sown in Fig. 4. The resulting refractive index fluctuations are called Brillouin backscattering. It is considered an inelastic phenomena, and takes the form of a light wave shifted $\left(v_{B}\right)$ in frequency domain from the original light wave frequency $\left(v_{o}\right)$ as shown in Fig. 3. This interaction leads to an up or downshift of the frequency of incident light as depicted in Fig. 3. The up-shifted part of the backscattered spectrum is called anti-Stokes scattering $\left(v_{o}+v_{B}\right)$, the down-shifted part Stokes scattering $\left(v_{o}-v_{B}\right)$, where Brillouin frequency shift $\left(v_{B}\right)$ is equal to acoustic wave frequency $\left(v_{a}\right)$ according to Fig. 4.

Brillouin frequency shift $\left(v_{\mathrm{B}}\right)$ is given by Eq. (1), where $n$ is the refractive index, $\lambda$ is the wavelength of the light, and $V o$ is the velocity of acustic wave obtained by Eq. (2).

$$
\begin{aligned}
& v_{\mathrm{B}}=\frac{2 n V o}{\lambda} \\
& V o=\sqrt{\frac{E}{\rho}}
\end{aligned}
$$

$V o$ is function of Young modulus $E$ and density $\rho$ of the material of the optical fiber core. When an optical fiber is externally perturbed by strain or temperature, the acoustic velocity in the core optical fiber changes and for this reason, the Brillouin frequency also changes. When Brillouin scattering occurs in the above conditions, the phenomenon is a spontaneous Brillouin backscattering. When a counterpart light is used to generate a Brillouin backscattering, the process is a stimulated Brillouin backscattering. In both cases, the most relevant issue in DOFSs development is that the Brillouin frequency shift $\left(v_{B}\right)$ is dependent on temperature or strain variations.

\section{Distributed optical fiber sensors}

Distributed optical fiber measurements would not be possible without the losses due to the attenuation and scattering in an optical fiber that are described above. The first DOFSs were based only in the attenuation measurement produced by external effects in Rayleigh backscattering process (Yu and Yin 2002 and Fang et al. 2012).

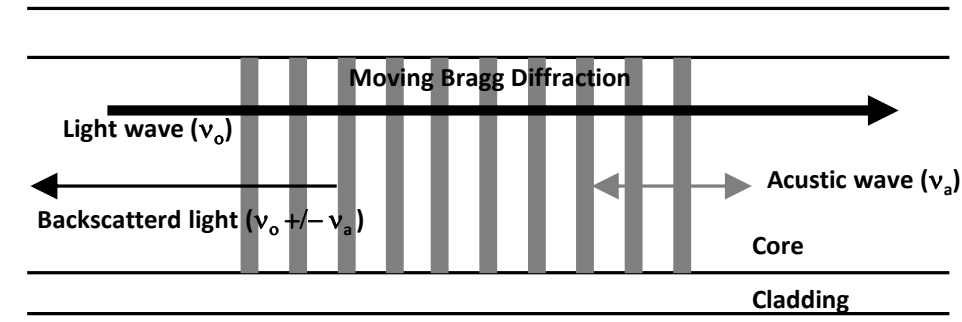

Fig. 4 Brillouin backscattering 


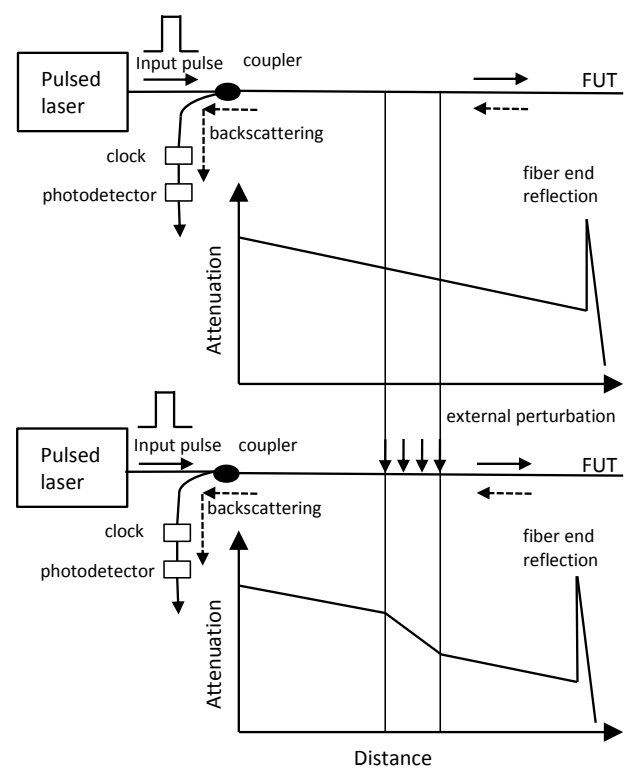

Fig. 5 Principle OTDR based on Rayleigh backscattering

Later, based on the opto-electronic system development, strain and/or temperature DOFSs were implemented. This strain DOFSs are based on intrinsic attenuation sources as Brillouin scattering. Thereby, strain DOFSs with several measured possibilities were developed and used in different SHM process. However, in SHM process where damage detection is the principal aim, DOFS based on Brillouin backscattering present some limitations. Basically, the main limitation is the spatial resolution. To overcome this limitation, recently, DOFSs that use Rayleigh backscattering were developed. Their principal characteristic is the high spatial resolution that could be obtained with them. Nowadays, depending on the specific aims of a SHM process, different DOFSs techniques are applied. Therefore, the principal characteristics of different DOFS techniques are described and compared to each other.

\subsection{Distributed sensing techniques}

\subsubsection{Optical Time Domain Reflectometer (OTDR)}

In an OTDR system, attenuation is the only measured parameter and its working principle is relatively simple. OTDR was proposed by Barnosky and Jensen (1976). Basically, an OTDR plots the attenuation of the backscattered light as a function of the time after an incident pulse is fired down the optical fiber (Hetch 2006). Light attenuation occurs due to Rayleigh backscattering that arises as a result of the random and microscopic variations in the refraction index as it was described above. Then, as shown in Fig. 5, when a pulse of light is launched into an unperturbed optical fiber, the attenuation decays exponencially with time due to the intrinsic loss in the fiber (Yu and Yin 2002). This is one of the principal reasons that OTDR is considered a linear backscattering system (Zeni 2009 and Fang et al. 2012). However, when an optical fiber is tested 
under a localized perturbation, attenuation will not decay according to the exponential issue at the unperturbed location. A sudden change in the curve is expected at the perturbed location, as also shown in Fig. 5 (Yu and Yin 2002).

As DOFSs and due to its low spatial resolution of $1 \mathrm{~m}$, the applications of OTDR in the SHM applications are limited. However, OTDR is a critical point in the development of others DOFSs with better spatial resolution and accuracy than OTDR. An OTDR system basically includes a pulsed light source, a coupler, a photodetector and a clock, as shown in Fig. 5. The light source sends out pulses of laser with a specific duration or pulse width. The pulses of laser get in a coupler where they travel only in a specific direction to the fiber under test (FUT). In the FUT, Rayleigh backscattering is produced, backscattered pulses of laser are routed to the coupler and then to the photodetector. Pulses of laser are not allowed to go directly from the light source to the photodetector (GN Nettest 2000). The photodetector measures the attenuation of the pulses of laser coming in from the FUT. It converts the optical power in the light to a corresponding electric level. A major component of the controller section is an accurate clock circuit which is used to precisely measure the time difference between when the pulses of laser are launched and when the backscattered light is detected. This round-trip pulse travel time light multiplied by the speed of light in the FUT, is used to calculate the round-trip distance. The distance from the OTDR to the measured point is the half of the round-trip distance (Palmieri and Schenato 2013). Finally, distance-attenuation graphics are obtained as shown in Fig. 5. As mentioned above, the major restriction of ODTR in SHM is the spatial resolution $(\Delta Z)$. If the spatial resolution is the smallest distance between two scatters that can be resolved (Yu and Yin 2002), in an OTDR the spatial resolution is in the order of meters. The spatial resolution is given by Eq. (3), where $c$ is the speed of light, $n$ is the fiber refractive index and $\tau$ is the pulse width.

$$
\Delta Z=\frac{c \tau}{2 n}
$$

Substituting typical values in equation (3), $c=3 \times 10^{8} \mathrm{~m} / \mathrm{s}, n=1.5$ and $\tau=10^{-8}$ s, get $\Delta Z$ $=1 \mathrm{~m}$, that is the OTDR smallest spatial resolution. Ideally, if in equation (3), pulse width $\tau$ is reduced, spatial resolution is increased. However, this reduction in the pulse $\tau$ may cause a decrease in the sensing distance range and above all, the detected signal-noise-ratio (SNR) may become poor, and distorting nonlinear effects could be produced (Palmieri and Schenato 2013). For certain distributed sensing requirements such as those in concrete structures, cracks width less than millimeters is an important issue, this spatial resolution may not be high enough. However, one of the first OTDR applications in the structural test field, was the cracking detection in concrete elements (Rossi and LaMaou 1989, Zako et al. 1995). Finally, it may also be noted that the direct collection of temperature or strain using an OTDR system is not possible. This is another restriction of OTDR technique in SHM.

\subsubsection{Brillouin Optical Time Domain Reflectometer (BOTDR)}

In 1989, Hirigochi, Kurashima and other authors, discovered the tensile strain and thermal effects dependence on the Brillouin frequency shift in optical silica fibers (Horiguchi et al. 1989, Kurashima et al. 1990). This is the starting point of DOFSs based on strain and temperature measurements using Brillouin backscattering. Brillouin optical time domain reflectometer (BOTDR) technique is based on the spectral evaluation of the spontaneous Brillouin backscattering, described in section 2.3. A technique similar to OTDR is employed, but in this case, strain and temperature are the measuring parameters obtained. Several setups have been developed 
by different research groups (Horiguchi et al.1995, Horiguchi et al. 1983, Niklès et al. 1997, Parker et al. 1997, Ohno et al. 2001). A typical configuration of BOTDR setup is showed in Fig. 6. The main task of a Brillouin sensor is to acquire the frequency shift $v_{B}$ (Fang et al. 2012), using a pulsed light that is launched into the FUT to generate spontaneous Brillouin scattering spectrum as shown in Fig. 3. Since the power in the backscatterd Brillouin signal is small, it can induce a negative effect on the quality of the measurements. To compensate this drawback a coherent detection is used (Galindez-Jamioy et al. 2012). The principal aim of coherent detection is fading noise to obtain better quality of data (Kurashima et al. 1997).

When a pulsed light travels into the optical fiber core, and longitudinal strain or temperature changes along the fiber are performed, the Brillouin frequency shift $v_{\mathrm{B}}$ changes in proportion to that variation of strain or temperature. These changes are showed with dashed curves in Fig. 3. BOTDR presents a practical adventage over OTDR technique. Temperature and strain variation can be obtained directly with BOTDR. Above all is because there are linear relationships between Brillouin backscattering and temperature and strain variations. These relationships are expressed by Eqs. (4) and (5) (Hotiguchi et al. 1995, Zhang and Wu 2008)

$$
\begin{aligned}
& v_{\mathrm{B}}(T o, \varepsilon)=C \varepsilon(\varepsilon-\varepsilon o)+v_{\mathrm{B} 0}(T o, \varepsilon o) \\
& v_{\mathrm{B}}(T, \varepsilon o)=C_{T}(T-T o)+v_{\mathrm{B} 0}(T o, \varepsilon o)
\end{aligned}
$$

where, $C \varepsilon$ and $C_{T}$ are the strain and temperature coefficients, respectively, and To and $\varepsilon o$ are the temperature and the strain that correspond to a reference Brillouin frequency $v_{\mathrm{B} 0}$. On the other hand, in BOTDR the position of strain in the fiber is determined by using the time interval between launching the pulsed light and observing the backscattering light. Also, the spatial resolution is determined by pulse width launched into the fiber as OTDR, and the maximum spatial resolution is $1 \mathrm{~m}$. The principal applications of BOTDR technique is in SHM of medium-span bridges (Bastiniani et al. 2005a, Bastiniani et al. 2005b).

\subsubsection{Brillouin Optical Time Domain Analysis (BOTDA)}

Brillouin optical time domain analysis (BOTDA) is based on stimulated Brillouin scattering. A pulsed laser with a frequency $v_{p}$ and a continouos wave $(\mathrm{CW})$ laser are injected into FUT from its two ends respectively, as shown in Fig. 7. The CW laser is tuned at frequency denoted $v_{c W}=$ $v_{p \pm} v_{B O}$, that is, reference Brillouin frequency shifted from that of the pulsed laser.

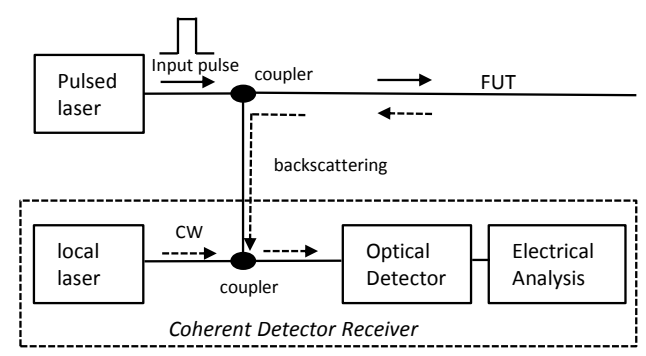

Fig. 6 Typical configuration of BOTDR setup 


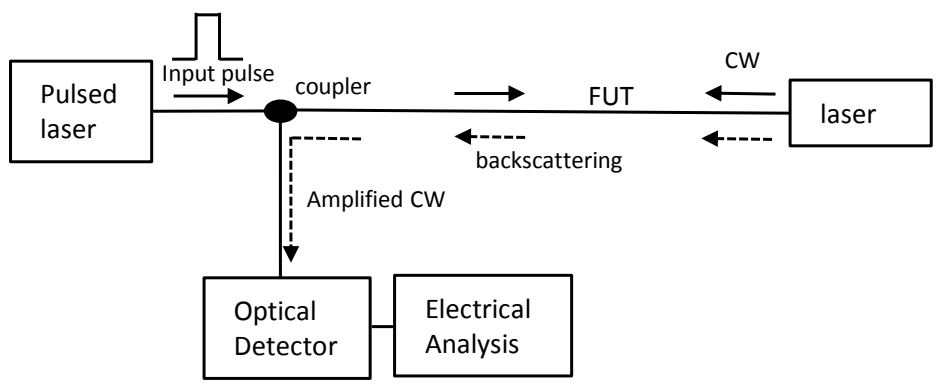

Fig. 7 Typical configuration of BOTDA setup

The interaction between the pulsed laser and CW laser leads to a larger scattering efficiency, resulting in an energy transfer from the pulsed laser to CW laser (Glisic and Inaudi 2012). A strong Brillouin backscattering is the result of above light interaction. Therefore, a monitoring system based on BOTDA is less sensitive to cumulated optical losses than BOTDR. This adventange is used in SHM systems that operate measurements over long distances. The monitoring of long span bridges or pipelines are some of their principal applications (Glisic and Inaudi 2012, Hoepffner 2008). However, BOTDA spatial resolution is limited by the acoustic waves or phonos lifetime of $10 \mathrm{~ns}$ produced in the Brillouin backscattering, as BOTDR, spatial resolution is limited to $1 \mathrm{~m}$.

On the other hand, access to both ends of the FUT is a condition to apply BOTDA technique, although using a mirror at one of the end of the fiber measurements with BOTDA can be obtained. However the optical fiber cable has to complete a close loop (Hoepffner 2008). In general, BODTR and BOTDA present a $1 \mathrm{~m}$ spatial resolution. The limiting factor is the extremely low intensity of the Brillouin backscattering, which makes it very difficult to increase the resolution (Samiec 2012). If one of the principal issues of a SHM is the damage detection, due to $1 \mathrm{~m}$ spatial resolution, DOFDSs based on Brillouin backscattering present a severe limitation. To enhance the capability of detecting the weak backscattering signal and increase the spatial resolution, several improving techniques have been used (Thévanaz 2010, Bao and Chen 2012) and new sensing systems have recently been developed which allows spatial resolution in $\mathrm{cm}$-range. Brillouin Optical Correlation Domain Analysis (BOCDA) (Hotate et al. 2002, Imai et al. 2010) is an example of these new technical developments. Nowadays, DOFSs based on Brillouin backscattering are used in laboratory tests or in SHM systems applied in civil structures as bridges, buildings, pipelines and railways (Ohno et al. 2001). In all of these applications, if the damage detection is one of the aims of the SHM process, complex algorithms (Ravet et al. 2009) and/or sophisticated devices (Shen et al. 2010) are used to obtain millimetric spatial resolution with DOFSs based on Brillouin backscattering. Recently, a system that uses Rayleigh backscattering to obtain distributed measurements with a spatial resolution in a millimetric range was developed. With this Rayleigh DOFSs, damage detection and non-uniform strain profiles in inhomegeneous material can be obtained. The basics and principal characteristcis of this Reyleigh DOFSs are described next. Nowadays, measuring systems based on Brillouin backscattering are the most DOFSs developed and applied in SHM of civil structures. 


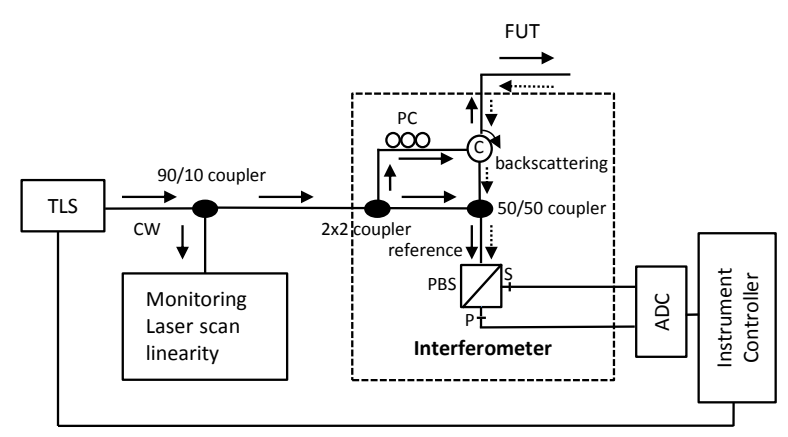

Fig. 8 Configuration of OBR setup

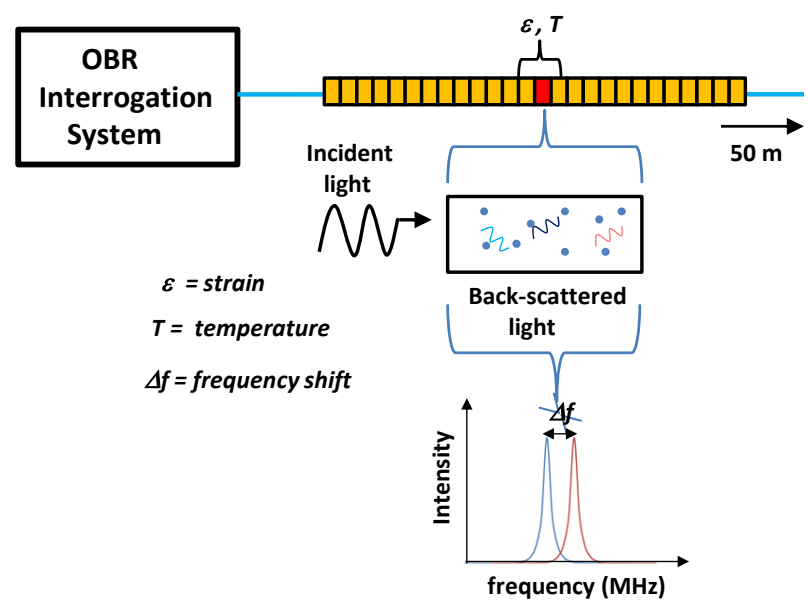

Fig. 9 Rayleigh scattering measurement process

\subsubsection{Optical Backscattered Reflectometer (OBR)}

Viewed in absolute terms, Rayleigh backscattering is also small, but significantly larger than Brillouin backscattering (Yu and Yin 2002) as shown in Fig. 3. However, Rayleigh backscattering is a linear phenomenon and to obtain nonlinear effects as temperature or strain variations using 1 $\mathrm{m}$ spatial resolution and attenuation effects is not possible. Recently a Rayleigh DOFSs with the possibility to obtain measurements with millimetric spatial resolution had been developed (Froggatt and Moore 1998a). This DOFSs is conformed as shown in Fig. 8. First, a CW produced by tunable laser source (TLS) is nonuniformly diverted at 90/10 coupler, a small amount of light, around $10 \%$, enters the optical network to monitoring laser scan linearity, the other $90 \%$ of the light goes to the sensing network (Lally et al. 2012). Inside the sensing network, one essential part is the reflectometer that provides a high spatial resolution. Here, a $2 \times 2$ coupler splits the $\mathrm{CW}$ in 
two arm, one of which contains the FUT, the other one is used as reference. Light passes through a polarization controller (PC) and circulator (C) before entering the FUT. Then, the light travels into the FUT and backscattering light is produced. The backscattering light is recombined through the circulator (C) with the light from the reference arm at 50/50 coupler. Then, a Polarization Beam Splitter (PBS) is used to split the reference light evenly between two orthogonal polarization states (Soller et al. 2006) and interference between backscattering light and each one of these two polarization states is recorded at detectors $\mathrm{S}$ and $\mathrm{P}$.

The signals from the $\mathrm{S}$ and $\mathrm{P}$ detectors are digitized in an Analogical-Digital Conversor (ADC) and send to an Instrument Controller for processing. The vector sum of the $\mathrm{S}$ and $\mathrm{P}$ signals results in a consistent measure of the Rayleigh scatter (Lally et al. 2012). TLS is used as source of light. Varying the frequency of the laser wavelength a periodical signal at the detector is created. The detector recives the backscattered signals from all the optical fiber segments simultaneously. In this process, the frequency of each segment depends on the location of the respective segment scattering the light back (Zhang and Wu 2008). The total signal must be split into its frequency components using an Optical Frequency Domain Reflectometry (OFDR) technique and Swept-wavelenght Interferometry (SWI) (Gifford et al. 2007). With SWI technique, the backscattered signal is divided into small windows of analysis in orders of centimeters, each of which is considered as a weak random FBG (Froggatt and Moore 1998b) and covers all the optical fiber length as shown in Fig. 9.

Then, the signals of each section are transformed into the frequency range, and a fluctuating reflection pattern depending on the frequency is obtained. This pattern could be named fingerprint or reference, because is absolutely stable when the measurement is repeated under unaltered external conditions (Samiec 2012). External temperature and strain changes of the fibre lead to a frequency shift, which is proportional to the changes of the external conditions that affect the fiber. Thanks to the use a SWI technique, distributed measurement over each small window of the fiber length is provided with millimetric spatial resolution as also shown in Fig. 9. OBR systems with high spatial resolution are limited to relatively short measurements lengths. Some hundreds of meters have been reported (Palmieri and Schenato 2013). However, OBR systems provide a high density points over short distances, filling a range of applications not easy covered by Brillouin DOFSs (Palmieri and Schenato 2013) as cracking detection in civil structures.

\subsection{DOFSs available}

Since 2002, when the first commercial DOFSs based on the Brillouin backscattering were implemented (Delepine-Lesoille 2008), the market had expanded to include at least five suppliers of Brillouin interrogation systems. In the spring of 2006 a DOFSs with millimetric spatial resolution and several meters limited measuring range had been in the market. The principal characteristics of all of these DOFSs are shown in Table 1. Also, DOFSs prototypes had been developed by different research groups (Bernini et al. 2011, Torres 2012). These prototype DOFSs were proved in laboratory test and field test with acceptable results.

Nowadays, measuring systems based on Brillouin backscattering are the most DOFSs developed and applied in SHM of civil structures. It is observed in Table 1 that, due to their large measurement range, DOFSs based on BOTDR and BOTDA techniques, can be very useful in evaluating large structures as long span bridges, tunnels and dams. Because in BOTDR techniques a pulsed light is launched only into one end of the optical fiber sensor, BOTDR systems are capable to still measure even in the case of one section of the optical fiber sensor is fail. This is not 
the case of BOTDA techniques, on which, the fiber optic sensor has to complete a close loop without failures. However, using the stimulated Brillouin backscattering, BOTDA applications in local evaluations as damage detection is possible, but only using complex methods to process signals and computational algorithms. On the other hand, BOTDR techniques are limited to damage detection due to their low spatial resolutions. On this last point and recently, a new distributed measuring technique was developed. OFDR technique based on Rayleigh backscattering had been applied as a new distributed measuring alternative to obtain a global and local structural evaluation). OFDR consists in measuring the frequency response of the signal, whose optical frequency is linearly swept in a bandwidth that extends to several tens of nanometers. According with Palmieri and Schenato (2013), this solution allows to achieve extremely high sensitivity and sub-millimeter spatial resolution as it was described in section 3.1.4. This technique is limited to measure medium large structures, but thanks to its high spatial resolution, detection, location and quantification of damage is possible. The next section briefly describes some applications of DOFSs to short and long term monitoring of a wide range of civil infrastructures.

\section{DOFSs deployed on in-service civil infrastructures}

Covering long distances, distributed measuring, interference-free and endurance, are some of the adventages of the DOFSs over traditional discrete measuring sensors. For these reasons, one of the principal applications of DOFSs in civil engineering is monitoring large structural systems. OTDR has been mainly applied to control damage in large geothecnical structures as dams or slopes. In these applications, the OTDR spatial resolution is enough to predict dangerous slope slides (Kreeber et al. 2010). Slopes (Shi et al. 2006), dams (Thévenaz et al. 1999, Inaudi and Glisic 2005), tunnels (Torres 2012, Li et al. 2010), piles (Iten 2011) and pipelines (Inaudi and Glisic 2005, Rajeev et al. 2013) have been monitored with BOTDR and BOTDA systems since several years.

Table 1 Commercially available DOFSs

\begin{tabular}{cccccc}
\hline \hline Company & System & $\begin{array}{c}\text { Measuring } \\
\text { Technique }\end{array}$ & $\begin{array}{c}\text { Measuring } \\
\text { range(max) } \\
\mathrm{km}\end{array}$ & $\begin{array}{c}\text { Spatial } \\
\text { resolution } \\
(\mathrm{m})\end{array}$ & $\begin{array}{c}\text { Strain } \\
\text { resolution } \\
(\mathrm{me})+/-\end{array}$ \\
\hline Yokogawa & AQ8603 & BOTDR & 24 & 1 & 1 \\
Sensornet & DTSS & BOTDR & 24 & 1 & 20 \\
Neubrex & Neubrescope NBX-6000 & BOTDA & 20 & 0.1 & N/A \\
Omnisens* & DiTeSt & BOTDA & 30 & 0.5 & 2 \\
OZ Optics* & Foresight & BOTDA & 40 & 0.1 & 0.05 \\
LUNA Tech* & ODeSi/OBR4600 & OFDR & $0.05-0.07$ & 0.001 & 2 \\
\hline
\end{tabular}

* several models $\quad \sim$ Based on Rayleigh backscattering 

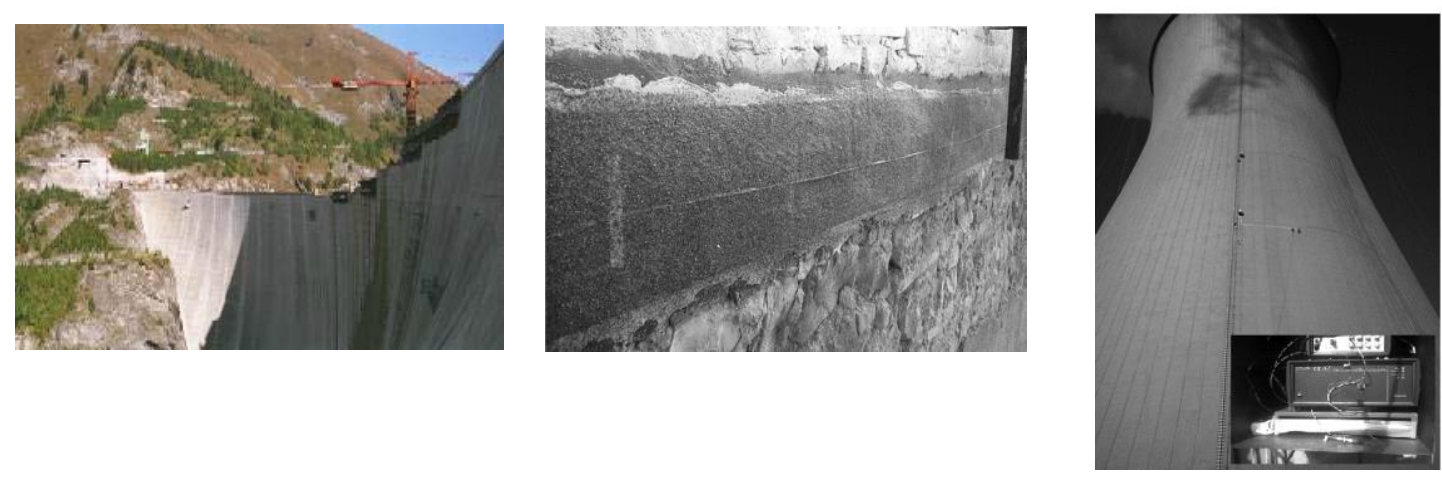

Fig. 10 Dam, masonry wall in a historical building and concrete cooling tower monitored by different DOFSs

In the specific case of the reference (Torres 2012), the behavior of three new prototypes of optical fiber sensor was compared. Discrete and long-gauge optical sensors were deployed simultaneously with DOFS based on BOTDA technique to obtain the temperature and strain variation on a tunnel section. According to the data obtained, the DOFS reproduce well the pattern of the structural behavior. The principal aim of these applications is to obtain a global evaluation of the structure and detect possible leakages or failures. However, to obtain the exact location and quantification of the damage is difficult due to the low spatial resolution of these systems. Other structures as historical buildings (Bastiniani et al. 2005a) and a concrete cooling tower (Casas et al. 2014) have been monitored with DOFSs. In the first case, a DOFS based on a BOTDR technique and AQ8603 system was used as a multi-distributed sensor embedded in a Fiber Reinforced Polymer (FRP) bonded by epoxy to a masonry wall. Thanks to this approach, strain distributed averaging can be obtained and the effectiveness of BOTDR technique had been verified even for reasonably weak strain levels. In the second case, an OFDR technique applied through ODiSI system was applied in the crack monitoring of a concrete cooling tower of $120 \mathrm{~m}$ high. This structure was instrumented in order to monitor the crack pattern due to wind forces and temperature effects and to observe the behavior before an after crack repair using the high spatial resolution of this technique. It is important to note, both the large size of the monitored structures as well as their diversity as shown in Fig. 10.

\subsection{Monitoring of bridge construction}

DOFSs are an attractive tool for monitoring bridges in service or a bridge complex construction process. Because of their complexity and magnitude during the construction of the Wu Gorge bridge, new techniques of supervision and monitoring were implemented (Tianguo et al. 2011) from 2001 to 2003, the construction period of this arch bridge $462 \mathrm{~m}$ long and $200 \mathrm{~m}$ high as shown if Fig. 11. DOFSs were used to monitor the local disengagement or cracks between concrete inward and the tubular steel section that conforms the main structure of the bridge as shown in Fig. 12. The monitoring was conducted without a monitoring system specifically designed for use in civil engineering. Specifically, local loss of contact between the steel structural system and filling concrete was monitored with embeeded optical fiber as shown in Fig. 12. The 
data capture system consisted of an OTDR that through Rayleigh scattering and the theory of microbending was able to measure losses on signals and the presence of cracks. The results were corroborated with those obtained through the implementation of an ultrasonic inspection.

\subsection{Monitoring static load tests on bridges}

Between 2005 and 2014 some monitoring examples of static load tests on bridges using DOFSs have been reported. Basically, all bridges were subjected to static loads produced by trucks according to a test program. Then, the strain measurements provided by different DOFSs were checked by comparison with data provided by other instruments, by analytical and numerical analysis, or by bridge design codes. Also, discussion on some important issues related to fiber installation on the structures is given. In 2005, BOTDR technique based on an AQ8603 commercial instrument was used to monitor two short span concrete bridges. The same research group conducted another test program with the same BOTDR system, this time in a larger bridge. The structural characteristics of the bridges and of the loading tests are described in Bastiniani et al. (2005b), Bastiniani et al. (2005c), respectively. These three bridges are shown in Fig. 13.

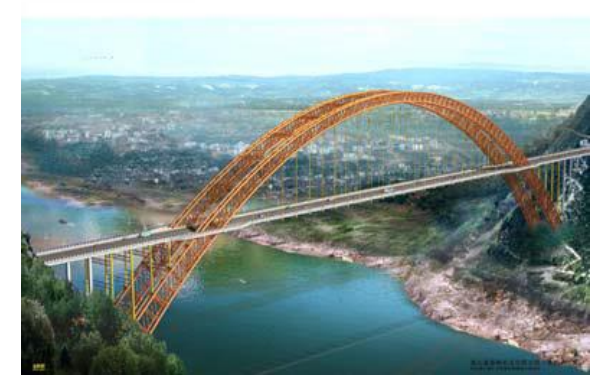

Fig. 11 Wu George bridge

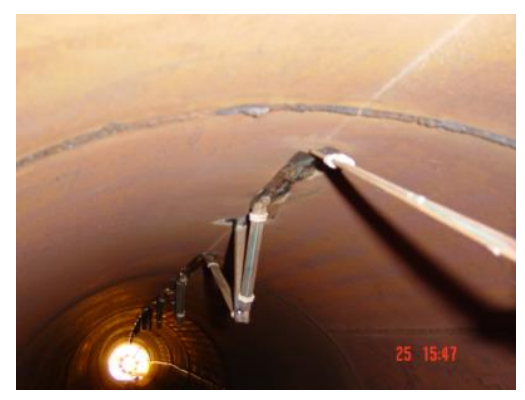

Fig. 12 DOFS in tubular section 

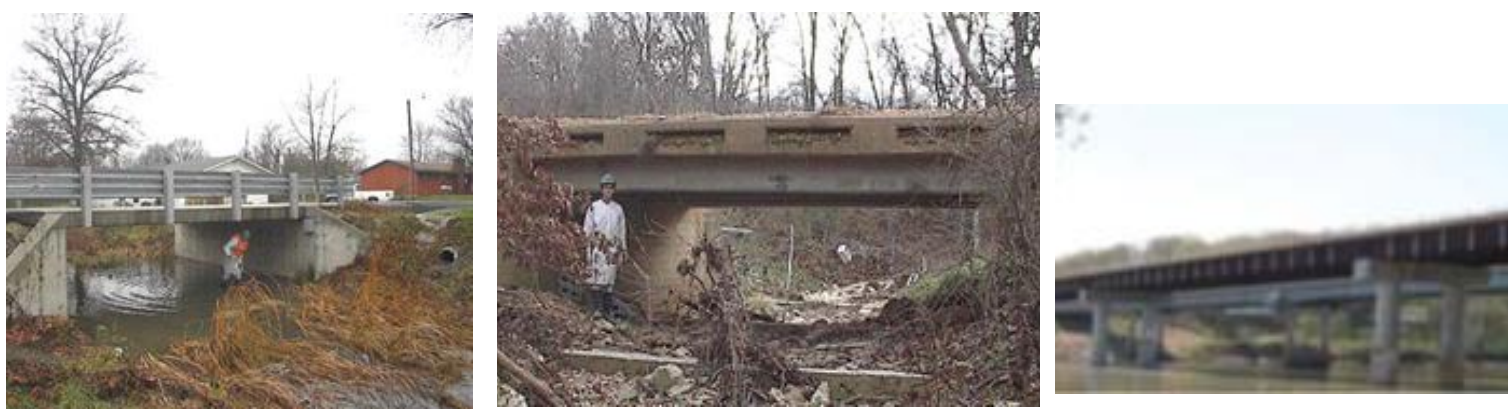

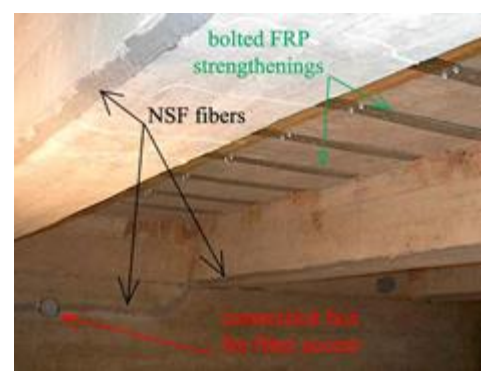

Phelps Country bridge

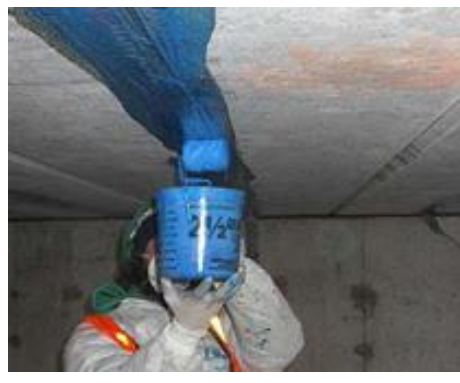

Walters Street bridge

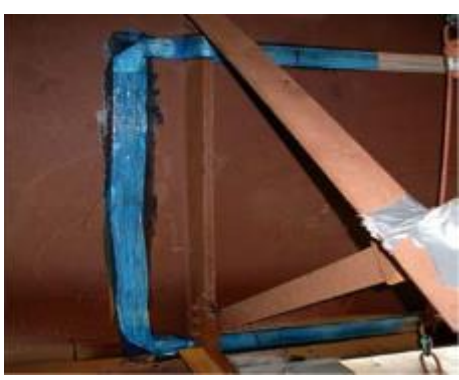

Bridge A6358

Fig. 13 Short-span bridges monitored by BOTDR technique based on AQ8603 system

A bare optical fiber was embedded in the beams of the Phelps Country Bridge built in 1900. A special FPR fiber was used and installed in the other two brigdes as shown in Fig. 13. In 2010, a bridge load test was used to investigate the effectiveness of the ODiSI system (Villalba et al. 2012, Casas et al. 2014) in measuring the strain along longitudinal prestressed concrete beams and reinforced concrete cantilevers. This application is important because a DOFSs with millimetric spatial resolution was used for the first time in a load test on a new concrete bridge. The bridge is shown in Fig. 14.
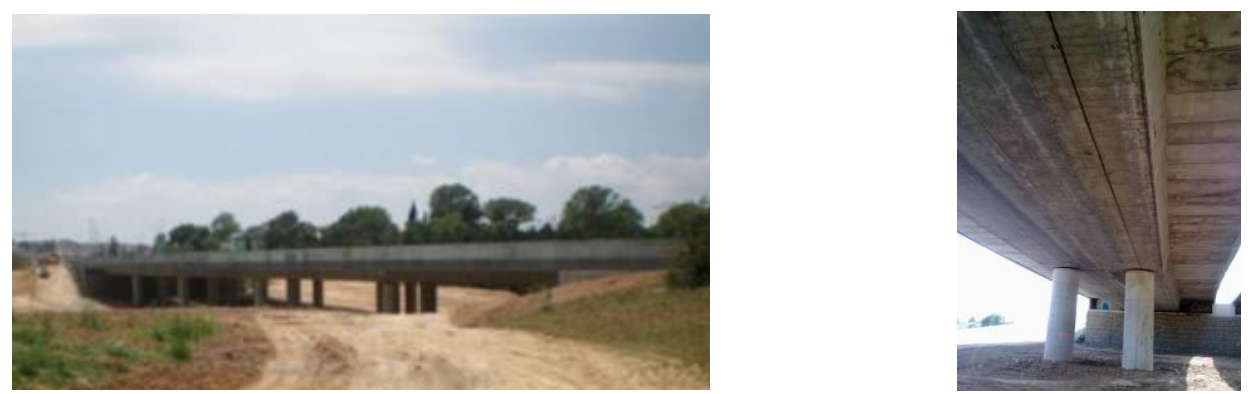

Fig. 14 Viaduct Road BP-1413 monitoring by ODiSI 

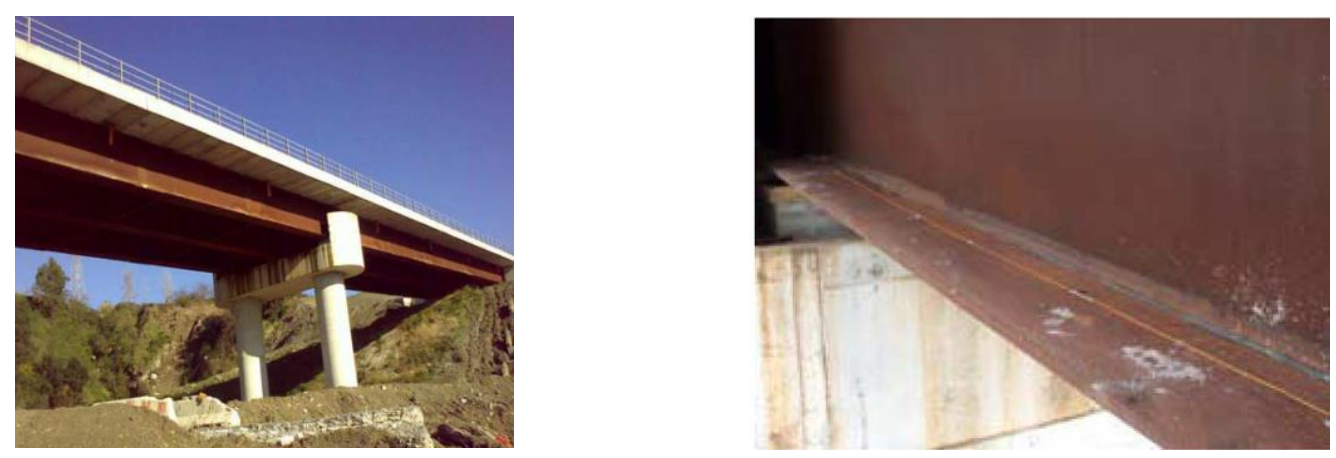

Fig. 15 Composite road bridge monitoring by a portable prototype BOTDA system

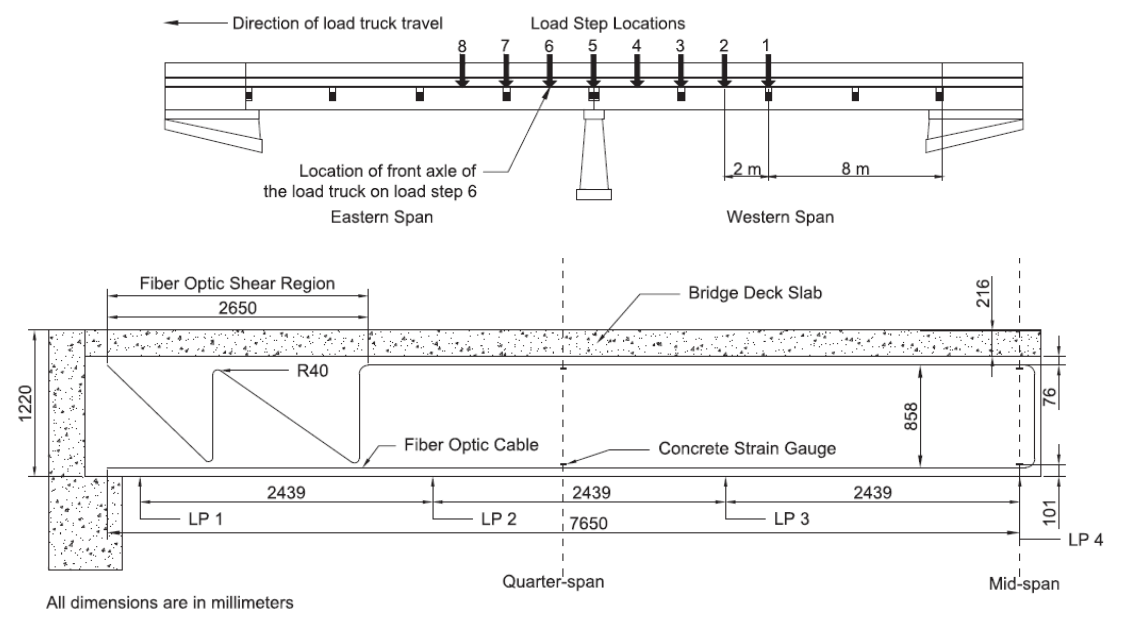

Fig. 16 Black River bridge monitoring by OBR4600 system

Similar field tests were reported in 2012 (Minardo et al. 2012a). In this case, the tests were performed not by a commercial system, but by a portable prototype system based on BOTDA technique. The tested bridge is showing in Fig. 15.

Recently in 2014, an OBR4600 system based on Rayleigh backscattering was used in the load testing of an old bridge in Canada built in 1933 (Regier and Hoult 2014). A schematic representation of the bridge is shown in Fig. 16.

In general, acceptable distributed strain measurements were obtained with the applications of all DOFSs. The DOSFs measurements were checked using the data obtained with other sensors as strain gauges, LVDT's, fleximeters, and by analytical and/or numerical analysis as FEM. In the old bridges (Bastiniani et al. 2005a, Regier and Hoult 2014), during passage of the trucks in some tests, the emergence of cracks was observed. However, the measurement of DOFSs system based on BOTDR technique indicated no change, reflecting a spatial resolution limitation (Bastiniani et al. 2005a). On the other hand, some strain profiles obtained during the tests indicate clearly the 
presence of cracks. Also, these applications are interesting because show a comparison between the deployement of different types of distributed optical fiber. In one of the bridges, optical fiber is embedded in the beams (Bastiniani et al. 2005a), in two others bridges a special manufactured optical fiber is adhered in concrete beams (Bastiniani et al. 2005a, Bastiniani et al. 2005b), and the optical fiber was bonded using different types of adhesives in the other bridges.

\subsection{Long term monitoring of bridges}

The prototype BOTDA sytem (Minardo et al. 2012a) was used in a reinforced concrete bridge, subject to monitoring for a period of one year, and under different environmental conditions. This bridge was designed to work uniformly and only in compression (Minardo et al. 2012b). Two standard single-mode optical fibers of silicon, were installed in parallel and fixed in two different ways, one with epoxy and the other with polyurethane. The experimental campaign shows variations in temperature of around 30 degrees Celsius. Measurements were performed during normal operation of the bridge. The fiber fixed with epoxy showed more consistent results. The last two lectures of measurements in the fiber fixed with polyurethane were not possible, due to the fiber breakage occurring during the test. Distributed strain measurements revealed the presensce of a crack around the $10.5 \mathrm{~m}$ fiber position as shown in Fig. 17. This crack was already open when the optical fiber was installed. The crack had a width in the order of $\mathrm{mm}$ and it was detected only visually but it was not measured, the corresponding strained region in the measurements was as large as $1 \mathrm{~m}$. This should be attributed to the $1 \mathrm{~m}$ spatial resolution of the prototype BOTDA system, and shows a limitation to obtain a pattern of the structural damage.

Another example to validate the use of optical fiber sensors in-service structures is the experience of the Streicker Bridge (Glisic et al. 2011, Glisic et al. 2013). Two optical fiber techniques were applied for almost 4 years to evaluate the structural behavior of this pedestrian bridge. The bridge is shown in Fig. 18. Instrumentation is based on global structural monitoring using discrete long-guage FBG sensors and integrity monitoring using a BOTDA system (Glisic et al. 2011, Glisic et al. 2013). In this project, the sensors were embedded in the concrete during the construction of the bridge as shown in Fig. 18, for this reason important observations had been made since the beginning of the operation of the bridge. The early age bahavior of the concrete was captured and cracking was detected (Glisic et al. 2013). A long-term objective of this project is to develop a framework of SHM as a tool for optimized bridge manegement Glisic et al. (2013).

The Götaälv bridge is the most complete monitoring field project in a long structure in service using a DOFSs (Enckell et al. 2011). DiTeSt system based on BOTDA technique is used in this metal bridge built in 1939, with a total length of $950 \mathrm{~m}$ and continuous seven steel beams. The bridge is shown in Fig. 19. The monitoring system BOTDA has a spatial resolution of $1 \mathrm{~m}$, which is sufficient for global monitoring of important changes. However, a method for early detection of cracks in metal structures based on advanced processing technique (Shen et al. 2010, Mufti et al. 2011) had been developed (Glisic and Inaudi 2011). SHM is planned for 15 years.

\section{DOFSs in laboratory tests}

Strain transfer between the optical fiber and host materials, and methods for damage detection are important aspects that have to be evaluated in laboratory to optimize the use of DOFSs in posterior field applications. On the other hand, DOFSs can be used as alternative of 
instrumentation in laboratory test to obtain data that using only discrete sensor is very difficult to measure. Next, some applications of DOFSs in different laboratory tests are described.

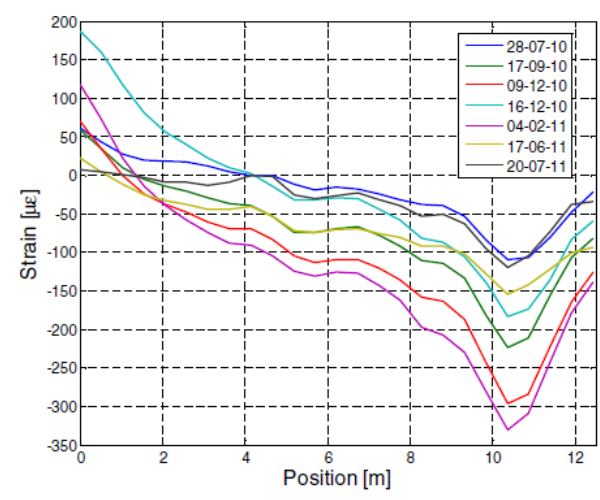

Fig. 17 Distributed compression strain measurement in the bridge
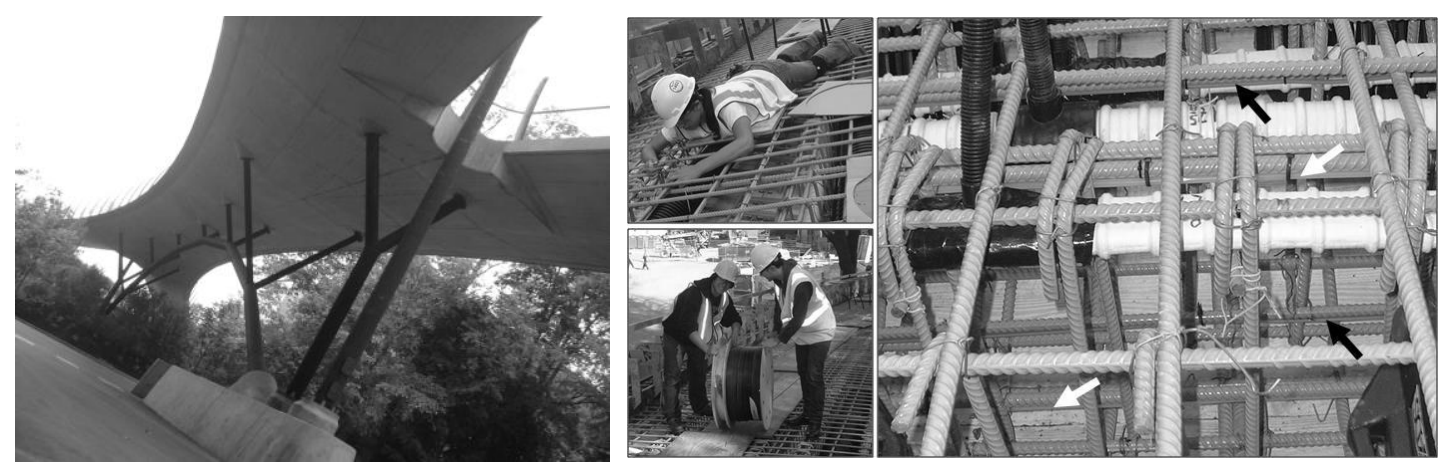

Fig. 18 Streicker bridge monitoring by DiTeSt system

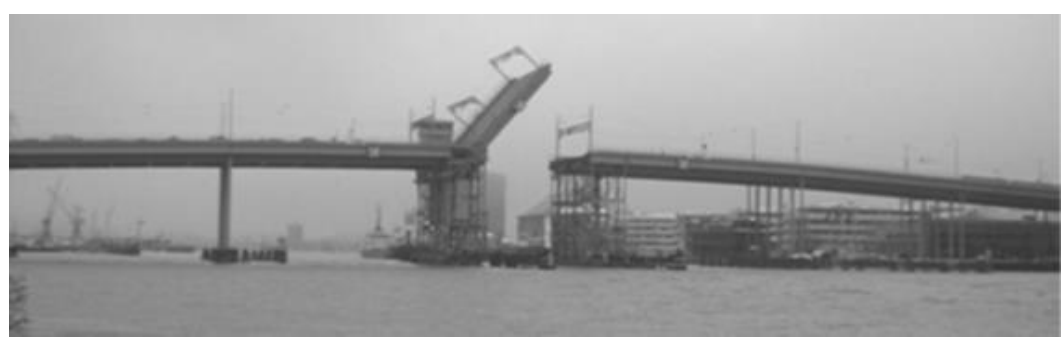

Fig. 19 The Götaälv bridge monitoring by DiTeSt system 

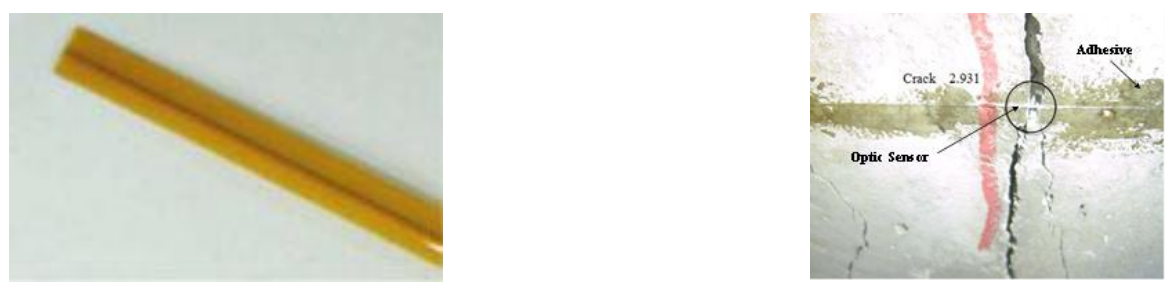

Fig. 20 Optical fiber with a coating and without coating

\subsection{Strain transfer mechanism between DOFS and the host materials}

Several mechanical tests (Ansari and Libo 1998, Duck and LeBlanc 200, Henault et al. 2012), pull out test (Henault et al. 2012, Billon et al. 2014) and FEM numerical models (Billon et al. 201479, Wan et al. 2008) had been developed to validate different methodologies to evaluate the strain transfer mechanism between DOFS and the host material. This is because when the optical fiber is protected with significant coating as shown in Fig. 20, strain profiles measured in the optical fiber may differ from actual strain in the structure ( $\mathrm{Li}$ and Wang 2003, Her and Wang 2011).

However, there are cases (Casas et al. 2014, Villalba and Casas 2013, Rodríguez et al. 2014), that the strain transfer can be neglected because the sensor used in the test is a fiber with a simply polyimide-coated, without any spatial protective coating, also shown in Fig. 20. Of course, the application of the last sensor may have strong limitations in the long-term monitoring of exposed structures. Other important issue in the application of DOFS in SHM is the installation of the optic sensor. Different adhesives are used to attach the optical fiber depending of the host surface. In general, in a field or laboratory optical fiber installation, firstly, bond areas are cleaned and free from grease with alcohol wipes. Then, a commercial glue as epoxy or cyanoacrylate is applied to the bond area, avoiding to apply adhesive in excess (Rodriguez et al 2015, Regier and Hoult 2014). Some authors as Hoult et al. (2014) and Regier (2013), have shown that in the laboratory environment and for steel surfaces, the installation of optical fiber with cyanoacrylate adhesive performs better than the use of epoxy or others adhesives. However, the use of epoxy adhesives in concrete, produces better measures than using cyanoacrylate adhesives.

\subsection{Crack detection in concrete elements}

Among the aims of SHM is the timely detection of cracks. Cracks need to be detected in an early stage of development and in general cracks are randomly distributed to the structure. Some research on the ability to implement distributed sensing using a single optical fiber to detect crack formation had been performed (Voss and Wanser 1994, Zou and Feng 2008). A large number of DOFSs based on the measuring losses with OTDR technique and microbendings in a single fiber optic were developed (Leung et al. 2000, Olson et al. 2005, Wan and Leung 2007, Liu et al. 2011). Correlations between losses, the number of cracks and crack width had to be obtained to evaluate the structural damage (Leung et al. 2005, Bao et al. 2010). For this reason, these methods are very limited in practical applications. In the case of DOFSs based on Brillouin backscattering, BOTDR and BOTDA systems offer typically a spatial resolution of $1 \mathrm{~m}$, however, there are several 
proposed methods to measure cracks in concrete structural elements using these systems (Klar et al. 2010, Shen et al. 2010, Feng et al. 2013). All these methods had been proved in laboratory with acceptable results, but they can still be improved. Some recent research prototypes in BOCDA technique exhibit better spatial resolution close to $3 \mathrm{~m}$ (Imai et al. 2010, Imai and Susuki 2011, Imai and Feng 2012). Different techniques have been developed to obtain continuous data easily. Recently, with the same ODISi system used in reference by Casas et al. 2015 and Villalba et al. 2012, a method to obtain crack initiation, location and width in a concrete structure subject to bending was proposed (Rodríguez et al. 2014, Rodríguez et al. 2015). The method is based on the test results carried out on a concrete slab (Villalba 2010, Villalba 2011, Villalba et al. 2013). Thanks to the millimetric spatial resolution of the system, a considerable number of spikes were observed in a distributed strain profile, indicating the detection of cracking even at low load levels as shown in Fig. 21 and when the cracking was still not visible. The peaks correspond perfectly well to the locations where cracking was also observed by visual inspection at a higher load level. This indicates a successful OBR response system against premature cracking. The results also show a good performance of distributed sensors, including loads close to the failure of the concrete specimen. Nowadays, there are others techniques as Smart Films (Zhang et al. 2006, Zhang et al. 2013, Zhou 2011), or Imagine processing (Caminero et al. 2013, Rouchier et al. 2013) for crack monitoring. The first one requires a spatial fabrication of the smart film and a carefully installation process. In the second one, the versatility of this system is limited. Therefore, DOFSs are a promising tool for crack monitoring in concrete structures, the installation is easy and the systems are small and compact.

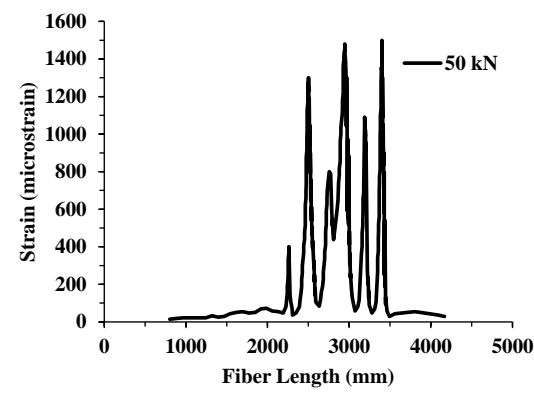

Fig. 21 Distributed strain profile performed by ODISi

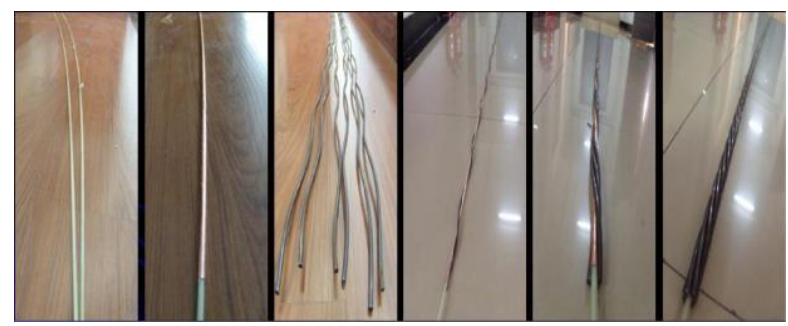

Fig. 22 Manufacturing of steel prestress cable 


\subsection{Monitoring the stress of post-tensioning cables}

For the safety of the prestressed structures, prestress loss is a critical issue. BOTDR technique had been applied to mesure the stress in post-tensioning cables. The DOFS can be bonded to the post-tensioning cable later on installed in the concrete beams. The BOTDR can be used to measure the stress distribution in a post-tensioning cable and the prestessing loss in the post-tensioning cable after several years can also be calculated (Gao et al. 2006). Nowadays, there are BOTDA experimental works using integrated optical fiber sensor inside the prestressing steel cables as shown in Fig. 22, obtaining acceptable results (Zhou et al. 2012, Lan et al. 2014).

\section{Conclusions}

An extensive review on the fundamentals and application of DOFSs in civil engineering structures has been presented, which proves that is technically feasible to apply this monitoring option in laboratory tests and field applications. The possibility to obatin continuous in the space data using DOFSs is the main advantage over other monitoring systems. Nowadays, depending on the aims of the SHM project, different DOFSs can be used based on their main performance, advantages and disadvantages. Long-span structures can be covered with BOTDA techniques, and also damage detection can be possible using these BOTDA techniques, but supported by signal processing techniques and complex algorithms. Recently, to cover the limited BOTDA spatial resolution, ODISi and OBR systems based on OFDR technique are an alternative to detect, locate and quantify structural damage with high spatial resolution. However, DOFS is still a recent technology and its reliability and accuracy in the real world is still an on-going process. For these reason, additional tests and real world experiences have to be performed to obtain a better understanding of DOFS in strain transfer between the optic fiber and the host material, and also in the crack detection and assessment of concrete structures in bending and shear. Nowadays, the cost of any commercial available DOFSs is high, but in general their installation and operation is easy comparing with the traditional SHM systems. For this reason, DOFSs can be used at several number of different SHM projects to average the initial cost of the equipment. Comparing with other technologies, DOFSs applications are very recent in SHM projects. However, when this technology proves successful, its demand will increase and the initial cost should be come down (Hoult et al. 2014).

\section{References}

Ansari, F. and Libo, Y. (1998), "Mechanics of bond and interface shear transfer in optical fiber sensors", $J$. Eng. Mech. - ASCE, 124(4), 385-394.

Bao, T.F., Wang, J.L. and Yao, Y. (2010), "A fiber optic sensor for detecting and monitoring cracks in concrete structures", Science China. Technol. Sci., 53(11), 3045-3050.

Bao, X. and Chen, L. (2012), "Recent progress in distributed fiber optic sensors", Sensors 12, 8601-8639.

Barnoski, M.K. and Jensen, S.M. (1976), "Fiber waveguides: A novel technique for investigating attenuation characteristics", Appl. Opt., 15(2), 2112-2115.

Bastianini, F., Corradi, M., Borri, A. and di Tomasso, A. (2005a), "Retrofit and monitoring of an historical building using "Smart" CFRP with embedded fibre optic Brillouin sensors", Constr. Build. Mater., 19, 525-535. 
Bastianini, F., Matta, F., Galati, N. and Nanni A. (2005b), “A Brillouin smart FRP material and strain data post processing software for structural health monitoring through laboratory testing and field application on a highway bridge", Proc. SPIE, 5765, 600-611.

Bastiniani, F., Rizzo, A., Galati, N., Deza, U. and Nanni A. (2005c), "Discontinuous Brillouin strain monitoring of small concrete bridges: comparison between near-to.-surface and smart FRP fiber installation techniques", Proc. SPIE, 5765, 612-623.

Bernini, R., Minardo, A., Ciaramella, S., Minutolo, V. and Zeni, L. (2011), "Distributed strain measurement along a concrete beam via stimulated brillouin scattering in optical fibers", Int. J. Geophys., Article ID 710941:1-5.

Billon, A., Henault, J.M., Quiertant, M., Taillade, F., Khadour, A., Martin, R.P. and Benzarti, K. (2014), "Quantitative strain measurements with Distributed Fiber Optic Systems: Qualification of sensing cable bonded to the surface of a concrete structure", Proceedings of the $7^{\text {th }}$ European Workshop on Structural Health Monitoring, Nantes, France, July.

Boyd, RW. (1992), Nonlinear Optics, Academic Press, USA.

Caminero, M.A., López-Pedroza, M., Pinna, C. and Soutis, C. (2013), "Damage monitoring and analysis of composite laminates with an open hole and adhesively bonded repairs using digital image correlation", Composites $B, \mathbf{5 3}, 76-91$.

Casas, J.R., Villalba, S. and Villalba, V. (2014), Management and safety of existing concrete structures via optical fiber distributed sensing Chapter of the book, Maintenance and Safety of Aging Infrastructure, (Eds., D.M. Frangopol and Y.Tsompanakis), CRC Press. Taylor and Francis

Casas, J.R. and Cruz, J.S. (2003), "Fiber optic sensors for bridge monitoring", J. Bridge Eng. - ASCE, 8(6), 362-373.

Culshaw, B. (2011), "Fiber optic sensors in smart structures: Achievements, challenges and prospects", Proc. of SPIE, 7982, 798202-1 798202-9.

Delepine-Lesoille, S., Merliot, E. and Gautier, Y. (2008), "Optical fiber strain sensors for use in civil engineering: State-of-the-art, industrialapplications and outlook”, BLPC no. 272,123-140.

Duck, G. and LeBlanc, M. (2000), "Arbitrary strain transfer from a host to an embedded fiber-optic sensor", Smart Mater. Struct., 9, 492-497.

Enckell, M., Glisic, B., Myrvoll, F. and Bergstrand, B. (2011), "Evaluation of large-scale bridge strain, temperature and crack monitoring with distributed fibre optic sensors", J. Civil Struct. Health Monit., 1(1), 37-46.

Fang, Z., Chin, K., Qu, R. and Cai, H. (2012), Fundamentals of Optical Fiber Sensors, Wiley.

Feng, X., Zhou, J., Sun, C.H., Zhang, X. and Ansari, F. (2013), "Theoretical and experimental investigations into crack detection with BOTDR-distributed fiber optic sensors", J. Eng. Mech. - ASCE, 139(12), 1797-1807.

Froggatt, M. and Moore, J. (1998a), "Distributed measurement of static strain in an optical fiber with multiple Bragg gratings at nominally equal wavelengths", Appl. Optics., 37(10), 1741-1746.

Froggatt, M., and Moore, J. (1998b), "High resolution strain measurement in optical fiber with Rayleigh scatter", Appl. Optics., 37(10), 1735-1740.

Galindez-Jamioy, C.A. and López-Higuera, J.M. (2012), "Brillouin distributed sensors: An overwiew and applications", J. Sensors, Hindawi Publishing Corporations.Article ID 204101, 17 pages.

Gao, J., Shi, B., Zhang, W. and Zhu, H. (2006), "Monitoring the stress of the post-tensioning cable using fiber optic distributed strain sensor", Measurement, 39, 420-428.

Gifford, D.K., Kreger, S.T., Sang, A.K., Froggatt, M., Duncan, R.G., Wolfe, S. and Soller, B. (2007), "Swept-wavelength interferometric interrogation of fiber Rayleigh scatter for distributed sensing applications", Proc of SPIE, 6770, 1-10.

Glisic, B. and Inaudi, D. (2007), Fibre optic methods for structural health monitoring, John Wyler \& Sons, Chichester, UK.

Glisic, B. and Inaudi, D. (2012), "Development of method for in-service crack detection based on distributed fiber optic sensors", Struct.Heatlh Monit., 11(2), 161-171.

Glisic, B., Chen, J. and Hubbell, D. (2011), "Streicker bridge: A comparation between Bragg-gratting 
long-gauge strain and temperature sensors and Brillouin scattering-based distributed strain and temperature sensors", Proc. of SPIE , 7981, 1-10.

Glisic, B., Hubbell, D., Hoeg, S.D. and Yao, Y. (2013), "Damage detection and characterization using long-gauge and distributed fiber optic sensors", Opt. Eng., 52(8), 1-12.

Glisic, B. and Inaudi, D. (2011), "Development of method for in-service crack detection based on distributed fiber optic sensors", Struct. Health Monit., 11(2) 161-171.

GN Nettest. Understanding OTDRs. (2000), Part\#33881. Rev. A. February.

Gómez, R., Murià, D., Mendoza, M.A., Mendez, A., Chandler, K., Sánchez, R.A., Escobar, J.A. and Csipkes, A. (2009), "Novel structural monitoring system for the Chiapas Bridge", Proceedings of the SHMII-4, Zurich Switzerland, July.

Henault, J.M., Salin, J., Moreau, G., Quiertant, M., Taillade, F., Benzarti, K. and Delepine-Lesoille, S. (2012), "Analysis of the strain transfer mechanism between a truly distributed optical fiber sensor and surrounding medium", Concrete Repair, Rehabilitation and Retrofitting III, 733-739.

Her, S.C.H. and Huang, C.H.Y. (2011), "Effect of coating on the strain transfer of optical fiber sensors", Sensors, 11, 6926-6941.

Hetch, J. (2006), Understanding Fiber Optics, Prentice Hall, Fifth Edition.USA.

Hoult, N.A., Ekim, O. and Regier, R. (2014), "Damage/deterioration for steel structures using distributed fiber optic stress sensors", J. Eng. Mech. - ASCE, October, 1-9.

Hoepffner, R. (2008), Distributed fiber optic strain sensing in hydraulic concrete and earth structures. measuring theory and field investigations on dams and landslides, Ph.D. Dissertation, Technische Univerität München, München.

Horiguchi, T., Kurashima, T. and Tateda, M. (1989), "Tensile strain dependence of Brillouin frequency shift in Silica optical fibers", IEEE Photonics Technol. Lett., 1(5), 107-108.

Horiguchi, T., Shimizu, K., Kurashima, T., Tateda, M. and Koyamada, Y. (1995), "Development of a distributed sensing technique using Brillouin scattering", J. Lightwave Technol., 13(7), 1296-1302.

Horiguchi, T., Shimizu, K., Kurashima, T., Tateda, M. and Koyamada, Y. (1983), "Brillouin optical time-domain reflectometry", IEICE Trans. Commun, E67-B, 4, 382-390.

Hotate, K. and Ong, S.S.L. (2002), "Distributed fiber Brillouin strain sensing by correlation-based, continuous wave technique, cm order spatial resolution and dynamic strain measurement", Proc. of SPIE, Photonics Asia, 299-310.

Housner, G.W., Berman, L.A., Caughey, T.K., Chassiakos, A.G., Claus, R.O. and Masri, S.F. (1997), "Structural Control: past, present and future", J. Eng. Mech.- ASCE, 123 (9), 897-971.

Imai, M. and Feng, M. (2012), "Sensing optical fiber installation study for crack identification using a stimulated Brillouin-based stra in sensor", Struct. Health Monit., 11(5), 501-509.

Imai, M. and Suzuki, H. (2011), "Highly dense strain measurement of concrete retrofitted with smart fabric", Proc. of SPIE, 7983,1-15.

Imai, M., Nakano, R., Kono, T., Ichinomiya, T., Miura, S. and Mure, M. (2010), "Crack detection application for fiber reinforced concrete using BOCDA-based optical fiber strain sensor", J. Struct. Eng. ASCE, 136(8), 1001-1008.

Inaudi, D. and Glisic, B. (2005), "Application of distributed Fiber Optic Sensory for SHM”, Proceedings of the $2^{\text {nd }}$ SHMII Conference, Shenzhen, China, November.

Iten, M. (2011), "Novel applications of distributed fiber-optic sensing in geothecnical engineering", Proceedings of the ETH, Zurich, Switzerland.

Klar, A., Goldfeld, Y. and Charas, Z. (2010), "Measures for identifying cracks within reinforced concrete beams using BOTDR", Proc. of SPIE , 7647, 1-9.

Krebber, K., Lenke, P., Liehr, S., Schukar, M., Wendt, M. and Witt, J. (2010), "Distributed POF sensors: recent progress and new challenges", Invited Paper, International Conference of Plastic Optical Fiber $(I C P O F)$, Yokohama, Japan.

Kurashima, T., Horiguchi, T. and Tateda, M. (1990), "Thermal effects on Brillouin frequency shift in jacketed optical silica fibers", Appl. Optics, 29(15), 2219-2222.

Kurashima, T., Tateda, M., Horiguchi, T. and Koyamada, Y. (1997), "Performance improvement of a 
combined OTDR for distributed strain and loss measurement by randomizing the reference light polarization satate", IEEE Photonics Technol. Lett., 9(3), 360-362.

Lally, E.M., Reaves, M., Horell, E., Klute, S. and Frogatt, M. (2012), "Fiber optic shape sensing for monitoring of flexible structures", Proc of SPIE, 8345, 1-10.

Lan, C.H., Zhou, Z. and Ou, J. (2014), "Monitoring of structural prestress loss in RC beams by inner distributed Brillouin and fiber Bragg grating sensors on a single optical fiber", Struct. Control Health Monit., 21(3), 317-330.

Leung, C.K.Y., Elvin N., Olson N., Morse T.F. and He Y. F. (2000), “A novel distributed optical crack sensor for concrete structures", Eng. Fract. Mech., 65(2-3), 133-148.

Leung C.K.Y., Olson, N., Wan, K.T. and Meng, A. (2005), "Theoretical modeling of signal loss versus crack opening for a novel crack sensor", J. Eng. Mech. - ASCE, 131(8), 777-790.

Li, C.H., Zhao, Y., Lui, H., Zhang, Z., Wan, Z., Chen, Y., Xu, X. and Xu, J. (2010), "Combined interrogation using a encapsulated fiber sensor in a tunnel", Struct. Health Monit., 9(4), 341-346.

Li, H.N., Li, D.S. and Song, G.B. (2004), "Recent applications of fiber optic sensors to health monitoring in civil engineering”, Eng. Struct., 26 (167), 1647-1657.

Li, Q., Li, G. and Wang, G. (2003), "Effect of plastic coating on strain measurement of concrete by fiber optic sensor", Measurement, 34, 215-227.

Lin, Y.B., Pan, C.L., Kuo, Y.H. and Chang, C.K. (2005), "Online monitoring of highway bridge construction using fiber Bragg grating sensors”, Smart Mater. Struct., 14, 1075-1082.

Liu, H.W., Chen, J., Sun, M. and Ding, R. (2011), "Theoretical analysis and experimental of micromechanics and mechanics-optics coupling of distributed optic-fiber crack sensing", Science China. Technol. Sci., 54(11), 185-191.

Liu, Y. and Nayak, S. Structural Health Monitoring: State of the Art and Perspectives. (2012), Journal of the Minerals, Metals and Materials Society JOM, 64(7), 789-792.

Majumder, M., Gangopadhyay, T.K., Chakraborty, A.K., Dasgupta, K. and Bhattacharya, D.K. (2008), "Fibre Bragg gratings in structural health monitoring-Present status and applications", Sensor. Actuat., 147(1), 150-164.

Minardo, A., Bernini, R., Amato, L and Zeni, L. (2012a), "Bridge monitoring using Brillouin fiber-optic sensors", IEEE Sensors J., 12(1), 145-150.

Minardo, A., Persichetti, G., Testa, G. and Zeni, L. (2012b), "Long term structural health monitoring by Brillouin fibre-optic sensing: a real case", J. Geophys. Eng., 9(4), 64-68.

Mufti, A., Thompson, D., Inaudi, D., Vogel, H.M. and McMahon, D. (2011), "Crack detection of steel girders using Brillouin optical time domain analysis”, J. Civil Struct. Health Monit., 1(3), 61-68.

Niklès, M., Thévenaz, L. and Robert, A. (1997), "Brillouin gain spectrum characterization in single-mode optical fibers", J. Lightwave Technol., 15(10), 1842-1851.

Ohno, H., Naruse, H., Kihara, M. and Shimada, A. (2001), "Industrial applications of the OBTR optical fiber strain sensor", Proceedings of Optical Fiber Technology 7, Invited Paper, 45-64.

Olson, N., Leung, C.K.L., and Meng, A. (2005), "Crack sensing with a multimode fiber: experimental and theoretical studies", Sensor. Actuat., 118(2), 268-277.

Palmieri, L. and Schenato, L. (2013), "Distributed optical fiber sensing based on Rayleigh scattering", The Open Optics Journal, 7, (Suppl-1, M7), 104-127.

Parker, T.R., Farhadiroushan, M., Handerek, V. and Rogers, A. (1997), “A fully distributed simultaneous strain and temperature Sensor using Spontaneous Brillouin Backscattering”, IEEE Photonics Technol. Lett., 9(7), 979-981.

Rajeev, P., Kodikara, J., Chiu, W.K. and Kuen, T. (2013), "Distributed optical fiber sensors and their applications in pipelines monitoring”, Key Eng. Mater., 558, 424-434.

Ravet, F., Brifford, F., Glisic, B., Niklès, M. and Inaudi, D. (2009), "Submillimeter crack detection with Brillouin-based fiber-optic sensors”, IEEE Sens. J., 9(11), 1391-1396.

Regier, R. (2013), Application of fiber optics on reinforced concrete structures to develop a structural health monitoring technique. M.A.Sc thesis, Queen's Univ., Kingston, ON, Canada.

Regier, R. and Hoult, N.A. (2014), "Distributed strain behavior of a reinforced concrete bridge: Case study", 
J. Bridge Eng. - ASCE, 1-9.

Rodríguez, G., Casas, J.R. and Villalba, S. (2014), "Assessing cracking characteristics of concrete structures by distributed optical fiber and non-linear finite element modelling", Proceedings of the $7^{\text {th }}$ European Workshop on Structural Health Monitoring, Nantes, France, July.

Rodríguez, G., Casas, J.R. and Villalba, S. (2015), "Cracking assessment in concrete structures by distributed optical fiber", Smart Mater. Struct., 24(3), 1-11.

Rogers, A. (1999), "Distributed optical-fibre sensing”, Meas. Sci. Technol., 10(8), 75-99.

Rossi, P. and LaMaou, F. (1989), "New method for detecting cracks in concrete using fiber optics", Mater. Struct., RILEM, Paris, 22(132), 437-442.

Rouchier, S., Foray, G., Godin, N., Woloszyn, M. and Roux, J.J. (2013), "Damage monitoring in fibre reinforced mortar by combined digital image correlation and acoustic emission", Constr. Buid. Mater, 38, 371-380.

Samiec, D. (2012), "Distributed fibre-optic tempetature and strain measurement with extremely high spatial resolution", Photonik International, 1, 10-13.

Shen, S., Wu, Z., Yang, C., Wan, C.H., Tang, Y. and Wu, G. (2010), "An improved conjugated beam method for deformation monitoring with distributed sensitive fiber optic sensor", Struct. Health Monit., 9(4), 361-378.

Shi, B., Sui, H., Liu, J. and Zhang, D. (2006), “The BOTDR-based distributed monitoring system for slope engineering", IAEG2006, paper 63.

Soller, B., Froggatt, D., Gifford, K. and Wolfe, M.S. (2006), Measurement of Localized Heating in Fiber Optic Components with Millimetric Spatial Resolution, Optical Society of America.

Tennyson, R.C., Mufti, A.A., Rizkalla, S., Tadros, G. and Benmokrane, B. (2001), "Structural health monitoring of innovative bridges in Canada with fiber optic sensors", Smart Mater. Struct., 10(3), 560-573.

Thévanaz, L. (2010), "Brillouin distributed time-domain sensing in optic fibers: state of the art and perspectives", Optoelectronics, China, 1-9.

Thévenaz, L., Facchini, M., Fellay, A., Robert, P.H., Inaudi, D. and Dardel, B. (1999), "Monitoring of large structures using distributed Brillouin fiber sensing", Proceedings of the Optical Fiber Sensors OFS 13 Conference.

Tianguo, T., Xinsheng, X. and Haowu, L. (2011), Health monitoring of civil infrastructure systems using distributed optical fiber sensors, Published by Sichuan University, Chengdu, China, School of Architecture and Environment and School of Water Resource and Hydropower.

Todd, M.D., Johnson, G.A. and Vohra, S.T. (2001), "Deployment of fiber Bragg grating-based measurement system in structural health monitoring application", Smart Mater. Struct., 10(3), 534-539.

Torres Górriz, B. (2012), Definición de las pautas y condiciones de monitorización, encapsulado y fijación de sensors de fibra óptica para la medida de deformación y temperatura de estructuras, Ph D. Dissertation, Technical University of Valencia, Valencia.

Villalba, S. and Casas, J.R. (2013), "Application of optical fiber distributed sensing to health monitoring of concrete structures", Mech. Syst. Signal Pr., 39(1-2), 441-451.

Villalba, S. and Casas, J.R. (2011), "Monitorización y salud estructural. Aplicación de la fibra óptica distribuida (OBR) en estructuras de hormigón", Proceedings of the V Congreso de Puentes y Estructuras $A C H E$, Barcelona Spain, October.

Villalba, S. (2010), Diseño y validación experimental de uniones mediante superposición de lazos de armaduras en viaductos de hormigón de sección transversal evolutiva. Optimización del proceso constructive, Ph. D Dissertation, Technical University of Catalonia, UPC, Barcelona.

Villalba, V., Casas, J.R. and Villalba, S. (2012), "Application of OBR fiber optic technology in structural health monitoring of Can Fatjó Viaduct (Cerdanyola de Vallés-Spain)", Proceedings of the VI International Conference on Bridge Maintenance, Safety and Management, IABMAS 12, Stresa, Italy, July.

Voss, K.F. and Wanser, K.H. (1994), "Fiber sensors for monitoring structural strain and cracks", Proceedings of the $2^{\text {nd }}$ European Conference on Smart Structures and Materials, Glasgow. 
Wan, K.T. and Leung, C.K.Y. (2007), "Fiber optic sensor for the monitoring of mixed mode cracks in structures", Sensor. Actuat. - A, 135(2), 370-380.

Wan, K.T., Leung, C.K.Y. and Olson, N.G. (2008), "Investigation of strain transfer for surface-attached optical fiber strain sensors”, Smart Mater. Struct., 17(3), 1-12.

Ye, X.W., Su, H. and Hau, P. (2014), "Structural health monitoring of civil infrastructure using optical fiber sensing technology: A comprenhensive review", The Scientific World Journal, Article ID 652329, 1-11.

Yu, F.T.S. and Yin, S. (2012), Fiber Optic Sensors, Marcel Decker, Inc.

Zako, M., Uragaki, H. and Kodate, K. (1995), "On intelligent structures using optical fiber (crack sensing using optical fiber)", J. JSMS, 44(499), 493-497.

Zeni, L. (2009), "Optical fiber distributed sensors: a tool for in-situ structural and environmental monitoring", Proceedings of the IWL- ${ }^{\text {st }}$ Italian Workshop on Landslides, Napoli, Italy, June.

Zhang, B., Wang, S., Li, X., Zhou, Z., Zhang, X., Yang, G. and Qiu, M. (2013) "Online bridge crack monitoring with smart film”, The Scientific World Journal, Article ID 303656,1-14.

Zhang, B., Zhou, Z., Zhang, K., Yang, G. and Xu, Z. (2006), "Sensitive skin and relative sensing system for real-time surface monitoring of crack in civil infrastructure", J. Intell. Mat. Syst. Str., 17(10), 907-917.

Zhang, H. and Wu, Z. (2008), "Performance evaluation of BOTDR-based distributed fiber optic sensors for crack monitoring", Struct. Health Monit., 7(2), 143-155.

Zhou, Z., He, J. and Ou, J. (2012), "Integrated optical fiber sensing system by combining large-scale distributed BOTDA/R and localized FBGs", Int. J. Distributed Sensor Networks, Articule ID 804394, $1-18$.

Zhou, Z., Zhang, B., Xia, K., Li, X., Yang, G. and Zhang, K. (2011), "Smart film for crack monitoring of concrete bridges", Struct. Health Monit., 10(3), 275-289.

Zou, L. and Feng, M.Q. (2008), "Detection of micrometer crack by Brillouin-scattering-based distributed strain and temperature sensor", Proc. of SPIE, 7004, 1-4. 